\title{
高圧蒸気滅菌装畐による大容量楽液の隇菌
}

\author{
鈴木一市, 石川安信, 川影逸郎, 藤井喜一郎 \\ 浜松医科大学医学部附属病院薬㓮部*
}

\section{Sterilization of Large Volume Solution by Autoclaving}

\author{
KAZUICHI SUZUKI, YASUNOBU ISHIKAWA, ITSURo KAWAKAGE, KIICHIRO FUJII \\ Pharmacy of Hamamatsu University School of Medicine Hospital*
}

(Received January 16, 1981)

\begin{abstract}
Temperature of large volume liquid in respective containers $(1-3 \ell)$ was continuously measured with thermocouple under autoclaving in order to determine the time for the temperature of the liquid to reach $115^{\circ}$. Sterilization temperature, regardless of a number of containers per load, was uniform even at various locations of the containers in the chamber. In spite of rapid rising and lowering of temperature, exhausting time was so long that the ingredients were decomposed. The size of containers was the most important factor in raising liquid temperature to $115^{\circ} ; 40 \mathrm{~min}$ for the $3 l$ container. The degree of sterilization was estimated from Log Inactivating Factor (LIF) based on a first-order reaction and the course of temperature under autoclaving. LIF was very useful for the determination of sterilization time, because it considerably agreed with a number of surviving $B$. stearothermophilus. The sterilization time of the $3 \ell$ container was thus determined at $60 \mathrm{~min}$ corresponding to LIF 11.
\end{abstract}

\section{は じめに}

薬液の隇菌に蒸気隇菌法が広く用いられている。この 滅菌法の条件は，J. P. X 飞も記載されているように “滅菌時間は，隇菌されるもののすべての部分が規定の 温度に達してから起算しなければならない”ことが前提 である. 病院薬局では使いやすさなどから 5 500 ml 以 外に $1 \sim 3 \ell$ の大容量の薬液を隇菌することがある. 大 容量の藥液は内部温度の上昇に長時間を要するといわれ ている1)。この上昇時間は個々の機種について異なり， それぞれ検討しなければならない。

小容量のアンプル中の薬液の分解を抑えるために高温 度まで急速に加熱する高速熱風やマイクロ波による隇菌 法が報告されている22．近年高圧蒸気滅菌法においてる 急速昇温, 急速冷却を行う装置が繁用されはじめた。し かし，このような装置は従来の装置より缶体内の昇温と 薬液の昇温により大きなずれを生じる危険性がある，そ こで著者らは, $0.5 \sim 3$ l 容量の薬液の隇菌条件について

* 浜松市半田町 $3600 ; 3600$, Handa-cho, Hamama tsu-shi, 431-31 Japan
検討し，若干の知見を得たので報告する．

\section{実 験 の 部}

\section{1. 実験材料}

容器は $20 \mathrm{ml}$ (日電理科硝子), $200,500,1000 \mathrm{ml}$ (以 上いずれも大河内硝子), 3 l (ギャマン) のバイアルび んを，薬液として精製水を使用した。

2. 装曋および温度の湘定

サクラ薬瓶隇菌装置 FYA-SLJP 200 形を用いた。こ の装置は, 間口 $60 \mathrm{~cm}$, 高さ $100 \mathrm{~cm}$, 奥行 $120 \mathrm{~cm}$ の角形 二重壁缶であり， 3 段格子状棚枠, 高温水に一定の水を 加えるバランス方式による急速冷却機構を備えている. 隇菌温度はすべて $115^{\circ} て ゙$ 行った。 びん内の隇菌温度は $500 \mathrm{ml}$ びんに留点温度計を挿入して測定した. 隇菌中の びん内の温度変化はクロメルアルメル熱電対温度計を用 い缶体外で自記記録した。

\section{3. 最大死隇菌数の測定}

生物学的インジィーターである隇菌テスパーS（栄研 器材）の試験法を準用した. 初発生菌数として試験紙に $10^{2} \sim 10^{7}$ まで 10 倍毎に変化させた Bacillus stearothe- 
rmophilus ATCC-12980 菌を含有させたインジヶータ 一をポリエチレンの袋に封入したのち，液の中央に埋没 して隇菌する. その後常法により $55^{\circ}, 72$ 時間培㕌し， 死隇の有無を判定した. 陰性と判定された初発生菌数の 最も多いインジケーターの菌数を最大死隇菌数として表 わした。

\section{結果および考寀}

\section{1. 隇菌工程中の温度変化}

滅菌工程のフローチャートを Fig. 1 亿示す. 本装置

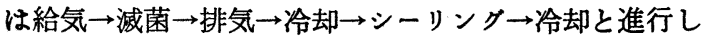
て滅菌が完了する.シーリングはミシン目入りの収縮チ ニーブをキャップに装着する工程である.この工程を組 み入れたことによりキャップシールの作業を省力化でき た.

缶体内の $115^{\circ}$ に到達する時間（ $t_{0} ）$ とびん内のそれ $\left(t_{s}\right)$ との差は, $500 \mathrm{ml}, 3$ lでそれぞれ約 10,40 分と容 量により 4 倍も到達時間にずれ（ $\Delta \mathrm{t} ）$ を生じている。 た, 急速昇温, 急速冷却に比較して排気時間 ( $\left.t_{\text {ex }}\right)$ か 30 分あり予想以上に長い。

\section{2. びんの位目と墄蔨温度}

缶体内のびんの位置が上段と下段では薬液の隇菌温度 が異なることがあるが3)，Table 1 亿示すように本装置 は缶体内のどの位置のびんも同一の隇菌温度を示してい る.この結果は, 給気工程における缶体内の空気の完全 な排除あるいはリフラッシュ機構によるるのと思われ ろ.

\section{3. 減菌温度到盖時間}

i ）びん内測温部の位置

びんの内部の位置と $\Delta \mathrm{t}$ の関係を把握するため測温部 を液中の任意の個所に保持して $\Delta \mathrm{t}$ を測定すると，Table 2 の上らに液面付近と底部の $\Delta \mathrm{t}$ の差が $3 l て ゙ 15$ 分, $1 \ell て ゙ 5$ 分と高さ方向に対して $\Delta \mathrm{t}$ が異なり底部の方が 昇温が遅い，中心部とガラスの内壁部ではほぼ同一の $\Delta \mathrm{t}$ を示す. この結果から, 以後の実験は $\mathrm{h} / \mathrm{h}_{0}=0.7$ の 位置で行った. 高さ方向にはびんの底面, 上部空間およ び側面の熱云導が複雑に関与しているが同一高さにおい ては水およびガラスの熱伝導係数がそれぞれ $6 \times 10^{5}$, $1 \mathrm{w} / \mathrm{m} ・ \mathrm{~K}^{4)}$ で水は $10^{5}$ 以上熱伝導が 良好なため $\Delta \mathrm{t}$ に 差がないと考兄られる。

ii）びんの容量および隇菌本数

Table 3 K $\Delta \mathrm{t}, t_{\mathrm{ex}}$ に扰よぼすびんの容量および隇菌 本数の影響を示した． $\Delta \mathrm{t}$ につて二元配㯰法による分 散分析の結果, 隇菌本数間には差が認められず容量間に は高度に有意差が認められた. $500 \mathrm{ml}, 1,3 \ell の \Delta \mathrm{t}$ は

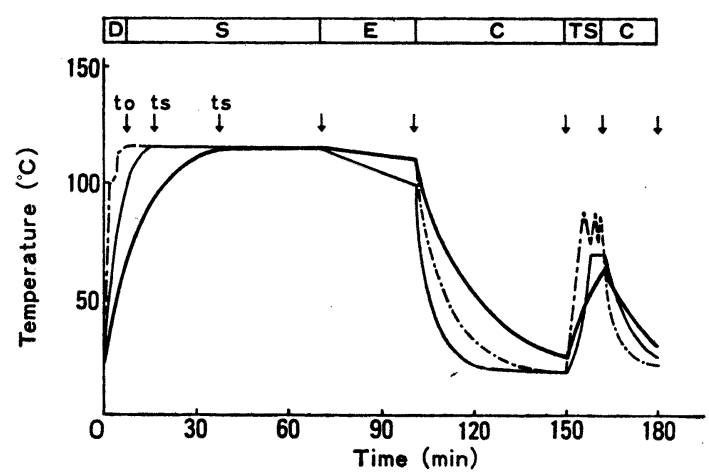

Fig. 1. Temperature Resulting from Sterilizing Solution and Chamber Operated at $115^{\circ}$

_. : Solution temp. in $3000 \mathrm{ml}$ container

- Solution temp. in $500 \mathrm{ml}$ container

- . : : Chamber temp.

D : Displacement $\quad \mathrm{S}$ : Sterilization

C : Cooling TS : Tube sealing

$t_{0}$ : Time required for chamber to reach $115^{\circ}$

$t_{s}$ : Time required for solution to reach $115^{\circ}$

E : Exhausting

Table 1. Sterilization Temperature of Container on Various Location in Chamber

(c)

\begin{tabular}{|c|c|c|c|c|c|}
\hline \multicolumn{2}{|c|}{ Location } & \multicolumn{2}{|c|}{$\bar{x}^{\text {Fi) }}{ }^{\text {ront }}{ }^{(1)}$} & \multicolumn{2}{|c|}{$\bar{x}^{\text {Inner }}{ }^{2)}$} \\
\hline Top & shelf & 114.4 & 0.6 & 114.3 & 0.6 \\
\hline Middle & shelf & 114.3 & 0.8 & 114.7 & 0.2 \\
\hline Bottom & shelf & 114.4 & 0.5 & 114.3 & 0.7 \\
\hline & \multicolumn{5}{|c|}{$\begin{array}{l}\text { 1) : Neighborhood of door in chamber } \\
\text { 2) : Neighborhood of baffle in chamber } \\
\text { 3) : Mean, } n=5 \\
\text { 4): Range }\end{array}$} \\
\hline
\end{tabular}

それぞれ 10〜13，16〜20，36〜42 分である. したがっ て，缶体内の温度が設定温度になると作動する隇菌タイ マーを30分にして 3 l の薬液を隇菌すると設定温度に到 達しないで工程が完了してしまう，隇菌本数により昇温 速度が異なる装置もあるが3)，本装置は本数すなわち被 隇菌物量に関保なく同一の温度上昇を示した。

$t_{\mathrm{ex}}$ は隇菌本数により著しく異なり，150 本の隇菌で は数本の隇菌に比較して 4 倍の50分も要している.この 現象は隇菌効果については望ましいといえるが分解し中 すい薬液には悪影警をおよぼすため十分注意しなければ ならない.

\section{4. 墄菌時問の設定}

i ） LIF の算出

各容量の薬液の隇菌に適した滅菌時間の算出に Log 
Table 2. Effect of Location of Thermometer to Measure Temperature in Container on Time Lag $(\Delta t)$ to Reach $115^{\circ}$

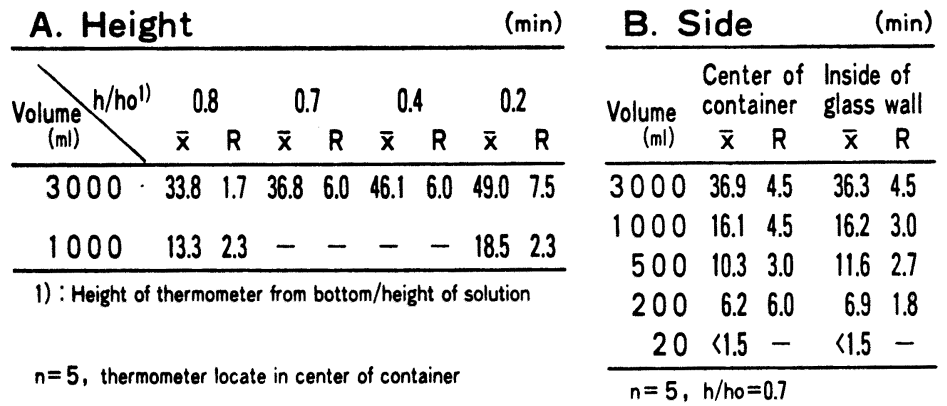

Table 3. Effect of Volume per Container and Number of Containers on Time Lag $(\Delta t)$ and Exhaust Time $\left(t_{\theta x}\right)$

\begin{tabular}{|c|c|c|c|c|c|c|c|c|}
\hline & \multicolumn{8}{|c|}{$n=5$} \\
\hline \multirow{3}{*}{$\begin{array}{l}\text { Time }(\mathrm{min}) \\
\text { Volume }(\mathrm{ml}) \\
\text { No. of } 500 \\
\mathrm{ml} \text { containers } \\
\text { per load }\end{array}$} & \multicolumn{6}{|c|}{$\Delta t$} & \multicolumn{2}{|c|}{ tex } \\
\hline & \multicolumn{2}{|c|}{500} & \multicolumn{2}{|c|}{1000} & \multicolumn{2}{|c|}{3000} & \multicolumn{2}{|c|}{500} \\
\hline & $\bar{x}$ & $\mathbf{R}$ & $\bar{x}$ & $\mathbf{R}$ & $\bar{x}$ & $\mathbf{R}$ & $\bar{x}$ & $\mathbf{R}$ \\
\hline 8 & 11.6 & 2.7 & 16.2 & 3.0 & 36.3 & 4.5 & 13.2 & 1.5 \\
\hline 80 & 9.5 & 4.5 & 16.0 & 10.3 & 39.0 & 7.5 & 21.4 & 13.5 \\
\hline 150 & 12.7 & 7.5 & 19.9 & 9.0 & 42.1 & 10.5 & 48.5 & 10.5 \\
\hline
\end{tabular}

Inactivation Factor (LIF) を用いた。 LIF は(1) 式の 初発生菌数 $\left(\mathrm{N}_{0}\right)$ を $\mathrm{t}$ 分処理後の生残菌数 $\left(\mathrm{N}_{\mathrm{t}}\right)$ で割っ た值の常用対数であり，この値はD値と同じ意味をるっ ているため隇菌の程度を示している，設定温度まで上昇 する時間, 室温まで冷却する時間を含めた加熱開始から 冷却終了までに全体としてどれたけ隇菌されたかを(2)式 のよらに表わし全体の $\operatorname{LIF}\left(\operatorname{LIF}_{(\mathrm{T})}\right)$ から隇菌時間の評 価を行っだ)。 また，LIF は死減速 度定数 (k) を用い ると(1)式になるため Fig. 1 の曲線をすとに次のように 各工程の LIF を算出した.

(1) 設定温度の工程の $\operatorname{LIF}_{(\mathrm{S})}$ は(1) 式をそのまま用い る.

(2) 温度 $(\mathrm{T})$ の変化に伴い $\mathrm{k}$ の変化する昇温, 排気, 冷却工程のそれぞれ $\operatorname{LIF}_{(\mathrm{b})}, \mathrm{LIF}_{(\mathrm{ex})} \mathrm{LIF}_{(\mathrm{c})}$ は図解 法により 6 分毎の小部分に分け，その中間温度に対 する $\mathrm{k}$ から各小部分の LIF を求めこれらの総和と する。

なお， T に対する $\mathrm{k}$ は Richards ${ }^{5)}$ の B. stearothermophilus についての (3) 式を用いた.

$\mathrm{LIF}=\log \left(\mathrm{N}_{0} / \mathrm{N}_{\mathrm{t}}\right)=\mathrm{k} \times \mathrm{t} / 2.303$

$\operatorname{LIF}_{(\mathrm{T})}=\mathrm{LIF}_{(\mathrm{h})}+\mathrm{LIF}_{(\mathrm{s})}+\mathrm{LIF}_{(e \mathrm{x})}+\mathrm{LIF}_{(\mathrm{e})}$ $\log \mathbf{k}=37.97815-14804 / \mathrm{T}$

$500 \mathrm{ml}, 3 l$ の LIF を Table 4 に示した. 隇菌タイ マーを30分にした時の $500 \mathrm{ml}, 3 \ell$ の $\mathrm{LIF}_{(\mathrm{T})}$ はそれぞ れ 8.0, 2.7 である. 局方の $115^{\circ}, 30$ 分の条件の LIF は 8.7 となり $500 \mathrm{ml}$ 容量では同程度の 隇菌を保障してい

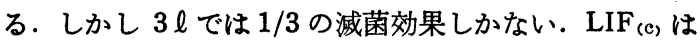
ほぼ 0 であり冷却期間中の減菌はまったく期待できない が昇温および排気工程では LIF が $2 \sim 4$ となり隇菌に かなり寄与していることがわかった.

$\mathrm{LIF}_{(\mathrm{s})}$ は $\mathrm{LIF}_{(\mathrm{T})}$ を任意に 設定すれば (2) 式より求めら れるが，かりに滅菌タイマーを 40,60 分として $\mathrm{LIF}_{(\mathrm{T})}$ の実測值を求めるとそれぞれ 6.6, 11.4 となり 3 l の大 容量の隇菌に60分を採用すれば局方の条件を満足する。

この条件は全工程中の死堿を考慮した場合であり，肩 方の隇菌温度における死隇すなわち $\mathrm{LIF}_{(\mathrm{s})}$ のみからは, いまだ不十分である. しかし，院内製剤の調製に捨水後 の蒸留水を用いれば隇菌前の生菌数の $10^{5}$ 個 /びん以上 の存在は考えられないため ${ }^{8} \mathrm{LIF}_{(\mathrm{s})}$ が5以上あれば $\mathrm{LIF}_{(\mathrm{T})}$ で評価して実用上は問題ないであろう.

ii) LIF と初発生菌数

LIF は加熱隇菌の 速度論を. 基礎とした 表示法のため ここで得られた LIF とB. stearothermophilus の最大 死隇菌数 $\left(\mathrm{N}_{\max }\right)$, すなわち, $\mathrm{N}_{t}=0$ になる $\mathrm{N}_{0}$ の最 大值との関係を求め Table 4 に示した. $3 l$ を $115^{\circ}$, 30分隇菌した場合には $\mathrm{N}_{\max }$ が $10^{5}$ であり, 調製時に $10^{8}$ 個以上の污染があれば生物学的インジケーターでは 陽性となり隇菌不十分と判定される． $\mathrm{N}_{\max }$ は 20,30 および40分滅菌した時に LIF から予想される値より 10 〜100 倍個高い傾向にある. この違いは, $115^{\circ}$ におけ るkが Richards の式では $0.666\left(\mathrm{~min}^{-1}\right)$, 河尻ら 式では $0.134\left(\mathrm{~min}^{-1}\right)$ となり, 菌株により熱抵抗性が異 なるために生じたと考えられる.いずれにしてる求めた 
Table 4. Relationship between Sterilization Time and Log of Inactivation Factor (LIF) or Number of Maximum Death Organisms Operated at $115^{\circ}$

\begin{tabular}{|c|c|ccccc|c|}
\hline $\begin{array}{c}\text { Volume } \\
(\mathrm{ml})\end{array}$ & $\begin{array}{c}\text { Sterili- } \\
\text { zation } \\
\text { Time } \\
(\mathrm{min})\end{array}$ & $(\mathrm{h})^{2)}$ & $(\mathrm{s})$ & $(\mathrm{ex})$ & $(\mathrm{c})$ & $(\mathrm{T})$ & Nmax \\
\hline & 10 & - & - & - & - & 0.10 & $\left\langle 10^{2}\right.$ \\
& 20 & - & - & - & - & 0.89 & $10^{2}$ \\
3000 & 30 & 1.65 & 0 & 1.06 & 0.02 & 2.73 & $10^{5}$ \\
& 40 & 2.57 & 2.03 & 2.02 & 0.02 & 6.64 & $>10^{7}$ \\
& 60 & 4.16 & 4.92 & 2.31 & 0.01 & 11.39 & $>10^{7}$ \\
500 & 30 & 2.07 & 4.34 & 1.62 & 0 & 8.03 & $>10^{7}$ \\
& 40 & 1.70 & 7.95 & 1.77 & 0 & 11.42 & $>10^{7}$ \\
\hline
\end{tabular}

1) : Each LIF calculated from Eq. I

2): (h),(s),(ex),(c) and(T) represent LIF during the period of rising temp., sterilizing period, exhaust period, cooling period and total LIF

3) : Number of maximum death organisms in a container

LIF の值と同程度の菌の減少がある.

実際の隇菌においては, 初発污染菌数によって生残菌 の存在する確率が変化し, 初発污染菌数を $10^{5}$ と考える と LIF が 8 で $10^{-3}, 11$ で $10^{-6}$ の確率で不良品が発生 することになる。薬液の分解のない滅菌精製水, 生理食 塩水には無菌を重視して LIF が 11 になる $500 \mathrm{ml}$ で 40 分, $3 l$ で 60 分の減菌タイマーの設定が 妥当と思われ る.

\section{結論}

大容量の薬液を高圧蒸気隇菌する場合, 薬液の温度の 変化が小容量の薬液の場合と著しく異なる. 従来の装置 と異なり缶体内のびんの位置あるいは本数が隇菌温度に 影響を与えなかった．大容量の薬液ではびん内の全薬液 が同じ昇温速度を示さず底部の薬液ほど昇温が遅い．急 速昇温, 急速冷却が行われる反面, 滅菌本数にも依存す るが，排気に長時間を要し薬液の 分解には好ましくな w.

隇菌温度への到達時間は, びんの容量に最も影響され $3 \ell$ の容量では $\Delta \mathrm{t}$ が 40 分にも達し, 容量毎に適切な減 菌時間を設定しなければならない，自記記録された隇菌
中のびん内温度の曲線から LIF を算出し減菌の程度を 把握する方法は, 生残菌の変動とかなり一致しこの隇菌 時間の設定に簡単に利用でさることが判明した。

\section{文䰚}

1) J.E. Hoover (ed.) : “Remington's Pharmaceutical Sciences", 15th ed. Mack Publishing Company, Easton, 1975, p. 1392 ; 日本公定書 協会編：“第九改正日本薬局方解説書”, 広川書 店, 東京, 1976 , p. B-520; 池田 憲, 田尻善和 : 薬剤学, 20, 198 (1960).

2）松下博一，松田三郎，河野正幸，鮫島政義，村上 香苗, 久保田喜郎, 高瀬邦彦: 薬剤学, 35, 106 （1975）; 水田栄治, 宇田良明, 朝日 豊, 河尻晴 三, 永松和夫 : 薬剤学, 36, 49 (1976).

3）青木 大: “病院薬局の実際”, 南山堂, 東京, 1973 , p. 282.

4）日本化学会編：“化学便覧”, 基礎編 II, 丸善, 東京, 1978 , p. 983.

5）綿貫 菬, 実川佐太郎，榊原欣作編：“滅菌法 消妻法”，第 1 集，文光堂，東京， 1974 .

6) 高野正彦: 月刊薬事，22，1435 (1980).

7）河尻晴三, 宇田良明, 永松和夫, 田中文彦, 並川 清: 薬剂学, 35, 183 (1975). 